\title{
Clinical and Pre-Clinical Evidence for Enteric $\alpha$-Synuclein Involvement in Parkinson's Disease
}

\author{
Eliyahu M Kochman, BS ${ }^{1}$, Kainat Akhtar, $B S^{1}$, Ali Alelayawi, $B S^{1}$ and Damian S Shin, MS, PhD ${ }^{1,2^{*}}$
}

${ }^{1}$ Department of Neuroscience \& Experimental Therapeutics, Albany Medical College, Albany, NY

${ }^{2}$ Department of Neurology, Albany Medical Center, Albany, NY

*Corresponding author: Damian Shin, MSc, PhD, Associate Professor, Department of Neuroscience \& Experimental Therapeutics, Department of Neurology, Albany Medical College, Albany NY, 12208, USA, Tel: 518-262-8627

\begin{abstract}
Parkinson's disease (PD) is the second most common neurodegenerative disease, presenting with the loss of dopaminergic neurons in the substantia nigra pars compacta (SNpc) and motor symptoms. Categorized as a synucleinopathy, the pathological hallmark of PD is intracellular filamentous Lewy bodies (LB), which are formed from protopathic aggregates. The most prevalent of these proteins is the presynaptic protein a-synuclein ( $\alpha$-syn). While commonly attributed to neuronal death in SNpc, postmortem studies have shown $\alpha$-syn immunoreactivity and LB pathology in the peripheral, central, and enteric nervous system (ENS). While the etiology of misfolded $\alpha$-syn is unknown, various gut microbiota and substrates are associated with a-syn dysfunction. Gastrointestinal (GI) dysfunction, a common feature in the prodromal phase of PD patients, and histological evidence have led to the Braak hypothesis of misfolded $\alpha$-syn commencement in the ENS and propagation to brainstem nuclei including the SNpc via the vagus nerve. Altered or stressed gut environment is thought to contribute to the misfolding of $\alpha$-syn that subsequently initiates or spurs its propagation from the gut myenteric plexus. This review covers clinical and pre-clinical evidence of the involvement of enteric a-syn in PD related to $\mathrm{GI}$ dysfunction and brain pathology.
\end{abstract}

\section{Keywords}

Braak staging, Gut microbiome, GI tract, Gastrointestinal, Prodromal Parkinson's disease, Gut-brain axis

\section{Introduction}

In 1817, James Parkinson published "An Essay on the Shaking Palsy" outlining the motor disease given his eponym "Parkinson's disease" (PD) [1,2]. PD is the second most common neurodegenerative disease [3] affecting $1-2 \%$ of those over the age of 60 [4]. Characteristic of PD is a marked reduction of dopaminergic neurons in the substantia nigra pars compacta (SNpc) [5] with coincident motor symptoms of bradykinesia, muscle rigidity, and resting tremors [6]. Lewy bodies (LB), the pathological hallmarks of PD first characterized by Fritz Lewy [7], are intracytoplasmic filamentous bodies [8] containing alpha-synuclein ( $\alpha$-syn) [9], neurofilaments [10], and ubiquitin [11]. Although LB are the key pathophysiological markers of PD, it is notable that LB coincide with SNpc neurodegeneration [12] but are generally a poor indicator of PD severity [13].

$\alpha$-syn is a 140 amino acid long protein largely, but not exclusively, localized to neuronal cells [14] that modulates synaptic vesicle activity and function [15]. The first report associating $\alpha$-syn with PD came from the discovery of a $\alpha$-syn gene (SNCA) missense mutation in Contursi families [16]. Further substantiation came as SNCA triplicate mutations were found to cause a doubling of intracytoplasmic $\alpha$-syn in PD patients [17], and SNCA polymorphisms were shown to increase the risk of developing PD $[18,19]$. Following these genetic studies, the direct link between $\alpha$-syn and PD pathology was revealed by an in vitro study that found exogenous $\alpha$-syn pre-formed fibril ( $\alpha$-syn-PFF) induction lead to phosphorylation, ubiquitination, and the recruitment of endogenous $\alpha$-syn to form LB-like pathology [20]. Thereafter it was shown that $\alpha$-syn-PFF induction in hippocampal neurons led to LB-like pathology, synaptic dysfunction, and neuronal death [21]. Next, unilateral

Citation: Kochman E, Akhtar K, Alelayawi A, Shin DS (2021) Clinical and Pre-Clinical Evidence for Enteric $\alpha$-Synuclein Involvement in Parkinson's Disease. Int J Neurodegener Dis 4:019. doi.org/10.23937/26434539/1710019

Accepted: May 06, 2021: Published: May 08, 2021

Copyright: (C) 2021 Kochman E, et al. This is an open-access article distributed under the terms of the Creative Commons Attribution License, which permits unrestricted use, distribution, and reproduction in any medium, provided the original author and source are credited. 
injection of $\alpha$-syn-PFF into the dorsal motor nucleus of the vagus (DMV) of mice revealed progressive $\alpha$-syn immunoreactive and LB-like pathology in the striatum, olfactory bulb (OB), and neocortex [22]. Cerebral inclusions increased as the study extended to 180 days postinjection (DPI) coinciding with marked motor deficits and a loss of tyrosine hydroxylase-positive (TH-positive) neurons [22]. Later studies utilizing cerebral $\alpha$-syn-PFF injection mirrored these results comprising of $\alpha$-syn pathology in non-human primates (NHPs) [23] and rats $[24,25]$.

While the mechanism of $\alpha$-syn neurodegeneration is unknown, $\alpha$-syn is shown to harbor cytotoxic potential selective to dopaminergic neurons [26] through the degeneration of dendritic spines [27], reduction of NURR1 expression [28], disruption of cellular pathways [29-32] and/or among other contributing factors [33]. Additionally, it was posited that $\alpha$-syn overexpression contributes to neurodegeneration and a reduction in neurotransmission [34]. This has led some to conclude that LB do not cause neurodegeneration, and may form solely as a preventative safeguard from misfolded $\alpha$-syn cytotoxic effects [35].

In the final chapter of his magnum opus, James Parkinson commented in his inability to connect the frequently observed gastric symptoms of his PD patients with brain pathology [1]. Yet, generalized gastrointestinal (GI) dysfunction, symptoms of constipation [36] and dysphagia [37] have been reported in PD patients prior to motor symptoms in the prodromal stage of the disease. In 2006, Braak and colleagues consolidated this gap by proposing the gut-brain axis [38] as a plausible explanation to link the GI and PD neural pathology based on previous post-autopsy studies [39]. Having found vast $\alpha$-syn inclusions in the GI myenteric plexus, they proposed that misfolded $\alpha$-syn seeded in the enteric nervous system (ENS) and propagated via an unknown pathogen through retrograde axonal and trans-neuronal pathways up the vagus nerve (VN) to the DMV [38]. As the disease progressed, these $\alpha$-syn inclusions ascended further to the SNpc and other midbrain areas [38] with the selectivity of $\alpha$-syn inclusions in the former due to SNpc neurons possessing thin long axons which are unmyelinated [40]. With that said, this review covers the related clinical evidence of enteric $\alpha$-syn role in PD and interrogation of the recent preclinical models of $\mathrm{VN}$ propagation of $\alpha$-syn.

\section{Clinical Evidence for ENS $\alpha$-Synuclein in PD Manifestation}

\section{Histological evidence of GI $\alpha$-synuclein}

LB are biochemical pathological hallmarks of PD found in the SNpc [5] and various other brain areas such as the cortex [41], albeit they are also located throughout the body. With regards to the latter, the presence of LB-like pathology was first noted in the myenteric plexus of the lower esophagus in post-mortem examinations of PD patients [42]. Further tissue analyses by Wakabayashi and colleagues [43] supported these findings with a later discovery of LB-like pathology spanning the upper esophagus to the rectum [44]. Subsequent autopsy studies reported $\alpha$-syn pathology in the esophagus [45-47], gastric wall [38,46], duodenum [46], alimentary tract [48], peripheral nervous system [47], cutaneous nerves [49], submandibular gland [47,50], and the appendix [51,52]. Body wide analyses also located $\alpha$-syn immunoreactivity in the spinal cord, sympathetic ganglia, sciatic nerve, genitourinary tract, respiratory, and endocrine systems $[46,53]$. A common highlight of these histopathological findings was the predominant aggregation of $\alpha$-syn in the myenteric plexus with the notable distinction that this plexus contains more postganglionic vagal fiber than the submucosal plexus [54]. Arguably, the most striking histopathological evidence emerged from human enteroendocrine cells (EECS) in the duodenum and colon which were shown to contain $\alpha$-syn [55]. From these findings, it was hypothesized that the close contact of EECs to the GI lumen, their neuron-like properties, and ability to propagate viruses to enteric neurons [56] provided a substrate pathway outlined by Braak and colleagues [38] and the cascading effect thereafter [55].

From findings revealed by the various autopsy studies, it was proposed that tissue biopsies could serve as an in vivo method of early PD diagnosis through positive $\alpha$-syn staining. This approach showed that phosphorylated $\alpha$-syn in prodromal PD patients, up to 20 year prior to PD diagnosis, was observed most often in the stomach and esophagus and others areas GI tract location [57]. Specifically, $\alpha$-syn immunoreactivity in the colon, rectum, appendix, and stomach was found in biopsies collected from PD patients with cancer [58] and their expression levels correlated with the severity of premotor symptoms [59]. With that said, there is considerable heterogeneity in the literature regarding the methodology with histological analyses, tissue collection, and organ choice for best detection, but a meta-analysis of PD biopsies posit that the highest diagnostic accuracy is achieved through the collection of skin biopsies and staining with anti-phosphorylated $\alpha$-syn antibodies [60]. As promising as biopsy studies may be, some nonetheless note that the usage of biopsies is not innocuous and that more, and long-term, studies are required to assign the full diagnostic utility of this approach [61].

\section{Appendectomies, vagotomies and $\alpha$-synuclein propagation}

The appendix is often considered as an organ with suppressed vestigial function. Anatomically, the appendix acts as part of the lymphatic system, assisting in the recognition and elimination of pathogens and the regulation of GI microbiota [62]. Noteworthy, $\alpha$-syn pathology has been colocalized to the mucosa, submu- 
cosal plexuses, myenteric plexuses, and nerve fibers of the appendix [62], suggesting that $\alpha$-syn in the appendix may propagate in the ENS due to the appendicular mucosa's lack of a blood-gut barrier. Consequently, it was hypothesized that appendectomies may prevent, or delay PD development. Concurring with this premise, a study of the Swedish National Patient Registry found that patients with an appendectomy had a $19.3 \%$ reduction of PD [62]. Moreover, appendectomies performed decades before the onset of PD coincided with a 1.6-year delay in PD onset [62] and motor symptom development [52]; underscoring the appendix's role in PD initiation. In juxtaposition, a study of Canadian individuals found no correlation between appendectomy with PD protection [63] whereas another study of Denmark citizens reported a slightly increased risk of PD development [64]. To this end, the inflammatory response associated with appendicitis was proposed as the mechanism of $\alpha$-syn misfolding, initiating retrograde VN propagation to the brain and the observed increase in incidence of PD [64].

Altogether, the aforementioned clinical studies provide indirect and correlative evidence of $\alpha$-syn seeding from the ENS to the brain via the VN. On the other hand, vagotomy studies may shed more insight on the validity of this proposition. A Danish population study observed that patients with a vagotomy displayed a $15 \%$ decreased risk of PD thereby denoting the importance of the VN in PD pathogenesis [65]. Yet, further analysis of the Danish population by others found no correlation between vagotomies and decreased risk of PD [66], and a recent study conducted on Swedish individuals concurred the lack of correlation between vagotomies and decreased PD risk [67]. Conversely, a slight correlation was shown between truncal vagotomy and decreased PD risk $[67,68]$. Commenting on the different interpretations, Breen and colleagues concluded that the vagotomy studies potentially lacked robust PD subclassifications and oftentimes overlooked the proinflammatory and organ control reorganization effects of vagotomies on PD outcome [69]. Thus, more research may be necessary to conclude the effect of vagotomies on PD development.

\section{GI Microbiota in PD Pathophysiology}

GI microbiota have been implicated in various neurodegenerative diseases including Alzheimer's disease (AD), Multiple sclerosis, and Amyotrophic lateral sclerosis [70]. Similarly GI microbiota, their dysbiosis and dysfunction, have been implicated in PD as the source of misfolded $\alpha$-syn [71]. Although the underlying mechanisms have not been completely elucidated, inflammation and increased autoimmune responses arising from this dysfunction may be key contributing factors to dopaminergic neuron degeneration [72]. In general, microbiome dysbiosis (marked by changes in microbiota) has been reported in PD patients [73]. Colonic microbiomes of $P D$ patients have shown a decrease in the butyrate producing bacteria of the genra Blautia, Coprococcus, and Roseburia, and increases in the genus Ralstonia [74]. PD fecal biome studies have similarly found increases in Clostridiales family XI, Lactobacillus, and the genus Peptoniphilus with a decrease in the genra Bacteroides, Faecalibacterium, and Fusicatenibacter $[75,76]$. A more recent study of PD patient GI biomes revealed that different abundance of some bacteria, specifically Prevotella, are present in fast-progressing PD patients [77]. However, it is important to note that significance between control and PD bacteria levels in the study varied depending on the statistical tool used [77]. Interestingly, small intestinal bacterial overgrowth was associated with worsening PD motor function, although not with symptoms of Gl dysfunction [68]. Given that various bacteria are implicated in this dysfunction, the role of microbiota is likely mediated by differing mechanisms. However, the role of microbiota in PD, either in the form of dysbiosis of infections, is likely due to their ability to cause inflammation and/or GI tract damage.

The noted bacterial heterogeneity found in PD has been linked to various mechanisms of pro- and anti-inflammation. The loss of butyrate-producing bacteria [74] could lead to a loss of anti-inflammatory protection since butyrate stimulates the generation and functionality of CD8+ T cells [78]. Fecal bacteria in PD also showed decreased metabolic genes and an increase in lipopolysaccharide (LPS) secretion genes [74]. The altered bacteria abundances in PD also correlated with lower levels of LPS binding protein (LBP) $[76,79]$, which could indicate immune system dysfunction and/or lowered secretion of cytokines. Yet, a fecal biome study found that cytokines IL-6, TNF- $\alpha$, hs-CRP, and DAO levels were no different between PD patients and controls [76]. With that in mind, there are other data to support an increased inflammatory response in PD given that concentration of the interleukins (IL)- $1 \beta$, IL-2, IL-4, IL-6, TNF-alpha and IFN-gamma have been found to be increased [80-83]. Notwithstanding, some find that proinflammatory cytokines and glial makers do not increase PD severity of related GI symptoms [83]. Nevertheless, the inflammatory potential of microbiota fills an important piece in the Braak hypothesis. Given that GI inflammation found in inflammatory bowel diseases [84] and irritable bowel syndrome [85] increases the risk of PD, there is credence to the idea that both inflammation and weakened $\mathrm{Gl}$ tract integrity can play a large role in PD pathogenesis. Mechanistically, the increase in GI tract permeability and susceptibility to GI environmental influences and oxidative stress on $\alpha$-syn seem to be underlying factors. Specifically, increased abundance of proinflammatory Escherichia coli, found in the sigmoid mucosa biopsies of PD patients, have correlated with increases in urinary sucralose (a marker for GI permeability) and LBP [79]. Furthermore, the increase in inflammation and GI permeability was associated with higher levels of $\alpha$-syn deposits and nitrotyrosine (a marker of 
oxidative stress) [79]. Noteworthy, all patients in that study exhibited symptoms of Gl dysfunction, but all had normal bowel movements marked by an absence of constipation [79]. Additionally, Helicobacter pylori have the specific ability to cause blood-brain barrier (BBB) malfunctions that cascades into increased microglia immune response and autoimmune neurotoxicity [86]. Such disruptions of the BBB can cause a loss of $\mathrm{TH}$-positive neurons, nigral dopaminergic neurodegeneration, an increase in glial inflammatory response, and astroglia activation [87]. This is important to note as epidemiological studies associate $H$. pylori infections with increased risk in PD development $[88,89]$. While some conclude that the role of $H$. pylori in PD is unclear given that $H$. pylori levels in PD patients were found to be similar to those in the general population [86], a Taiwanese population study compared the rates of PD in those with $H$. pylori infections against those in the general public. The study yielded a significantly higher occurrence of PD in those with a history of $H$. pylori infections [90]. As a point of interest, the study commented that the increased rate of PD was only displayed in those over 60 years of age [90], suggesting a progressive accumulation of microbiome dysfunction occurring over decades.

\section{Nascent Therapies for PD Related Dysfunction}

Given the high rates of GI symptom occurrence in PD and constipation effecting $60-80 \%$ of PD patients [91] up to $10-20$ years prior to motor symptoms [91-93], experimental and ameliorative treatments have been proposed. Simplest of all, some propose the detection of GI symptoms as a method of early PD diagnosis [94] since changes in specific bacteria, such as decreased Prevotellaceae levels in PD patient fecal biomes, coincide with increased GI dysfunction [95]. This also supposes that the constipation often present in PD is caused by Gl dysbiosis. To compliment this proposition, treatment with probiotics to repopulate the GI flora has successfully been implemented to alleviate PD-associated constipation [96-98]. Fecal microbiota transplantation (FMT) has likewise been used to treat constipation, with the first case report finding increased gastric motility and decreased leg tremors following FMT transplant through transendoscopic enteral tubing [99]. Soon thereafter, others found FMT relieved motor and non-motor symptoms of PD and that FMT transfer via colonoscopy was more efficacious than via a nasal-jejunal tube [100]. The caveat with this up-and-coming treatment is FMT donor-recipient compatibility seems to be the greatest factor in the successful treatment of PD constipation since it affects the acceptors ability to regrow flora [101]. However, the 'ideal' healthy donor for therapeutics is vaguely denoted with sparse literature on the topic; although, those having Lactobacillus and Bifidobacterium appear to provide the most replicable efficacy in treating PD-related constipation [101]. Nonetheless, the therapy is promising given that FMT transfer is relatively simple with few adverse effects.

\section{Pre-Clinical Models of the Gut and $\alpha$-Synuclein}

Although clinical studies provided correlative indication for the role of the gut biome in PD manifestation, a causational link to enteric $\alpha$-syn was lacking. Recent preclinical studies using animal models brought to light how GI dysbiosis and microbiota substrates may be directly involved in $\alpha$-syn misfolding. Specifically, LPS found on the outer membrane of gram-negative bacteria can cause neuroinflammation and a loss in $\mathrm{TH}$ positive neurons in the SNpc [102]. In addition, LPS can also mutate $\alpha$-syn into fibril forms in mice [103]. Enterobacterial Curli protein amyloid fibers produced by $E$. coli have likewise been shown to produce brain and GI $\alpha$-syn inclusions which coincided with neuroinflammation and an increase in microglia and cytokines [104]. The study also noted that the production of $\alpha$-syn-misfolding amyloids is not limited to $E$. coli given that other prevalent human GI microbiota produced similar amyloids [104].

While the general focus of GI microbiota is on their pro-inflammatory and synucleinopathic characteristics, it should also be mentioned that Bacteroides ovatus, Eggerthella lenta, and E. coli possess the ability to synthesize bioactive, and $\alpha$-syn protective, phenolic acids. In mice and transgenic (Tg) Drosophila with an alanine 53 to threonine (A53T) mutation, bioactive phenolic acids can prevent $\alpha$-syn protofilaments and fibril formation and improve motor function [105]. This implies that declined microbiota function could lead to a loss of protective factors and subsequent $\alpha$-syn malformation. Moreover, microbiota function appears to play a pivotal role in motor dysfunction by regulating microglia function [106]. Microglia have been shown to activate in the presence of $\alpha$-syn [26] and to phagocytize $\alpha$-syn affected neurons $[23,107]$. On the other hand, $\alpha$-syn overexpression can elicit microglia and motor dysfunction [108], although this dysfunction was found to be reversible through treatment with short-chain fatty acids and antibiotics that modulate microbiota function $[106,108]$. This implies that microbiota serve a pro-microglia role that may help prevent neuron-neuron spread of $\alpha$-syn. Conversely, other preclinical studies illustrated that $\alpha$-syn may be the cause of GI dysfunctions. Specifically, studies in Tg A53T mice reported that misfolded $\alpha$-syn expression caused constipation, decreased colon contractions [109], and decreased gastric motility pre-symptomatic to motor deficits [110]. Notably, vagotomies performed on these animals resulted in the complete loss of GI $\alpha$-syn pathology and dysfunction [110]. There was also a gradual decrease in $\alpha$-syn immunoreactivity in the myenteric plexus in aged A53T mice, but no change in DMV $\alpha$-syn immunoreactivity [110]. While a mechanism was not provided in these studies, it was apparent that $\alpha$-syn played a role in GI dysfunction. 


\section{a-Synuclein Vagus Nerve Propagation Models}

\section{The first model of vagus nerve propagation}

The original hypothesis of enteric sourced $\alpha$-syn as outlined by Braak, et al. [38] was derived from histology data, but with little delineated details about the explicit role of $\alpha$-syn in LB formation and propagation. Even as the evidence for $\alpha$-syn in LB formation continued to increase [20-25], the phenomenon to propagate via the VN had not yet been explicitly supported by data. Now, subsequent studies investigated this gap in knowledge with the first involving $3 \mu$ injections of $\alpha$-syn at five locations of the intestinal wall in the stomach and duodenum of wild type (WT) Sprague-Dawley rats. Sacrificed at 12 hours post-injection (HPI), histological assessment revealed $\alpha$-syn pathology in the intestines, progressing at 48 and $72 \mathrm{HPI}$ with $\alpha$-syn pathology emerging in VN fibers and the DMV. Notably, there was no $\alpha$-syn immunoreactivity at $24 \mathrm{HPI}$ in choline acetyltransferase-positive (ChAT-positive) DMV neurons [111] underscoring a time-dependent mechanism for $\alpha$-syn propagation. Yet, ChAT-positive neurons of the DMV ultimately exhibited $\alpha$-syn pathology, but at $6 \mathrm{DPI}$. The study tested the various $\alpha$-syn forms (monomeric, oligomeric, and $\alpha$-syn-PFF at $1 \mu \mathrm{g} / \mu \mathrm{l}$, and lysate at $2 \mu \mathrm{g} / \mu \mathrm{l}$ ) and found that all were able to propagate to the DMV, but the monomeric and oligomeric forms coincided with the strongest immunostaining [111]. To explain the mechanism of spread, it was proposed that $\alpha$-syn propagation was mediated via microtubules with a rate of $20-30 \mathrm{~mm} /$ day of translocation [111]. While previous studies aligned $\alpha$-syn induction with cell death $[21,22]$, the study emphasized that the lack of cell death in the DMV and $\alpha$-syn pathology in the SNpc and locus coeruleus (LC) was the result of dose and time required for $\alpha$-syn incubation and cytotoxicity [111].

\section{Conflicted evidence of vagus nerve propagation}

Building upon this model [111], a subsequent group injected $\alpha$-syn into the GI tract of Sprague-Dawley rats and NHPs. For the former, $\alpha$-syn-PFF and monomers were administered at $2 \mu \mathrm{g} / \mu \mathrm{l}$ at a volume of $5 \mu \mathrm{l}$ in six locations into the descending colon. In the latter, NHPs received the same $\alpha$-syn injection paradigm except a larger volume of $10 \mu \mathrm{l}$ was used and repeated nine times into the colon and once in the stomach. Tissue analysis post- $\alpha$-syn-PFF injection showed ubiquitous $\alpha$-syn immunoreactivity in the myenteric plexus of the colon at 1, 6, and 12 months post-injection (MPI). Interestingly, at $6 \mathrm{MPI}$ of monomeric $\alpha$-syn, immunoreactivity decreased in comparison to $1 \mathrm{MPI}$. Notwithstanding this finding, $\alpha$-syn expression at $12 \mathrm{MPI}$ returned to the levels found at $1 \mathrm{MPI}$. Collection of fecal material and endpoint metrics of colonic motility revealed that both $\alpha$-syn-PFF and monomers correlated with decreased fecal output and water content. Brain stem assays $1 \mathrm{MPI}$ revealed that there was minor $\alpha$-syn immunoreactivity in rats injected with $\alpha$-syn-PFF, but none in monome- ric-injected rats. When the VN was extracted and dissected to assess propagation, $\alpha$-syn immunoreactivity was present in the VN but none in the spinal cord. Similarly, while NHPs at $12 \mathrm{MPI}$ exhibited gut pathology as noted in rats, there was no $\alpha$-syn immunoreactivity in the central nervous system (CNS) including the DMV [112]. This discrepancy in VN propagation may be due, in part, to the translocation rate outlined by Holmqvist, et al. [111] given that the length of the VN in NHPs is longer than in rats. Presumably, more time may be required for $\alpha$-syn to reach the DMV and further location in the larger animal model. Still, the absence and variability of $\alpha$-syn immunoreactivity led Manfredsson and colleagues to raise questions regarding the gut-brain axis model [112].

In the same year, Uemura and colleagues [113] used a similar animal model but injected $8 \mu$ of mouse $\alpha$-synPFF $(2 \mu \mathrm{g} / \mu \mathrm{l})$ into eight locations in the gastric wall of male $\mathrm{C} 57 \mathrm{BL} / 6 \mathrm{~J}$ mice. Cervical hemi-vagotomies were performed on a subset of mice to prevent VN propagation. At 45 DPI, $\alpha$-syn immunoreactivity was observed in the muscular and submucosal layers of the gastric wall and ChAT-positive neurons of the DMV. Importantly, $\alpha$-syn immunoreactivity was absent in the spinal cords of all cohorts at 23 and 45 DPI and in DMV in the subset of mice which received hemi-vagotomy surgery. Curiously, sparse expression of $\alpha$-syn was visible at 12 MPI. The authors postulated that this was either due to DMV neurodegeneration or weak $\alpha$-syn inability for neuron-to-neuron propagation [113]. While $\alpha$-syn levels have been shown to cause DMV neurodegeneration [41], the lack of further brain inclusions suggests the latter as the plausible explanation.

\section{Vagus nerve propagations producing extensive ce- rebral inclusions}

Until now, studies investigating VN $\alpha$-syn immunoreactivity and $\alpha$-syn propagation into the brain provided an unclear consensus about its validity in PD. More recently, studies reported that enteric $\alpha$-syn caused progressive LB-like pathology in the brains of rats [114] and mice [115]. In the former study, rats were injected with $3 \mu \mathrm{l}$ of $\alpha$-syn-PFF $(1 \mu \mathrm{g} / \mu \mathrm{l})$ at six sites in the pylorus and duodenum. Neuropathological analysis conducted at 4 MPI found $\alpha$-syn immunoreactivity in the OB, striatum, hippocampus, thalamus, hypothalamus, substantia nigra (SN) and various cortices [114]. Interestingly, $\alpha$-syn immunoreactivity was also discovered in the celiac ganglion and the heart [114]. Similarly, Kim and colleagues injected mice with $2.5 \mu \mathrm{l}$ of $\alpha$-syn-PFF in 2 sites in the pylorus and upper duodenum and found expressed $\alpha$-syn immunoreactivity in the myenteric plexus, DMV, medulla oblongata (MO), and LC at $1 \mathrm{MPI}$ [115]. Greater $\alpha$-syn immunoreactivity was found at $3 \mathrm{MPI}$ in previously observed sites in addition to new inclusions that seeded in the SN, amygdala, hypothalamus, and prefrontal cortex [115]. As the monitored period lengthened, fur- 
ther increased density in these sites were observed at 7 $\mathrm{MPI}$ along with new inclusions in the $\mathrm{OB}$ with behavior tests revealing cognitive impairment [115]. Interestingly, there was a decrease in $\alpha$-syn immunoreactivity in the $\mathrm{SN}$ and $\mathrm{MO}$ at $10 \mathrm{MPI}$, while other areas exhibited increased $\alpha$-syn density and expression. The experimental design also included a comparison of the propagational ability between $\alpha$-syn-PFF and monomers of mouse origin and human $\alpha$-syn-PFF. Neither mouse monomer or human $\alpha$-syn-PFF elicited $\alpha$-syn immunoreactivity in the $\mathrm{SN}$, while mouse $\alpha$-syn-PFF produced extensive pathology [115]. Importantly, a truncal vagotomy coincided with a lack of $\alpha$-syn immunoreactivity in the brain and SNCA null mice injected with $\alpha$-syn-PFF did not exhibit $\alpha$-syn immunoreactivity in the CNS or gut [115]. Remarking on past studies and findings [111-113], Kim and colleagues surmised that the previous lack of CNS $\alpha$-syn inclusions were likely due to decreased ratios of $\alpha$-syn-PFF injected relative to animal body weight, the use of large $\alpha$-syn-PFF (>100 nm) and selecting injection sites that were poorly innervated by the VN [115].

\section{Exogeneous $\alpha$-synuclein and GI dysfunction}

While previous studies investigated enteric $\alpha$-syn propagational efficacy, they did not focus per se on connecting propagation with $\mathrm{Gl}$ dysfunction and physiological changes. Filling this gap, a more recent study has since provided data to substantiate a tight coupling between $\alpha$-syn and GI distress. Specifically, $7 \mathrm{DPI}$ of $3 \mu \mathrm{l}$ of $\alpha$-syn-PFF and monomers $(1 \mu \mathrm{g} / \mu \mathrm{l})$ into the duodenum in mice increased production of inflammatory cytokines such as IL- 6 and cellular proliferation of myenteric cells [116]. The findings posited that $\alpha$-syn can recruit immune responses in the Gl tract. Subsequently, the duodenum at $21 \mathrm{DPI}$ expressed a decrease in myenteric ganglia and an increase in enteric glial cells which increased over time [116]. There was also a decrease in GBA1 transcription and lysosomal enzyme Glucocerebrosidase production at $7 \mathrm{DPI}$, although production returned to pre-injection amounts at 120 DPI [116]. Concurring with previous studies [111-115], $\alpha$-syn immunoreactivity were seen in the duodenum at $60 \mathrm{DPI}$, which subsequently reduced at $120 \mathrm{DPI}$. Decreased striatal dopamine and increased $\alpha$-syn immunoreactivity brainstem were also seen [116], although the inclusions were less extensive than preceding studies $[114,115]$. Behaviorally, mice exhibited declining cognitive and motor function at 60 and $90 \mathrm{DPI}$, but these symptoms improved at $120 \mathrm{DPI}[116]$. Notwithstanding the variability, $\alpha$-syn was concluded to have a pro-inflammatory effect and to disrupt ENS activity and glucocerebrosidase production [116] (Table 1 and Table 2).

\section{Discussion}

Despite increasing evidence supporting enteric $\alpha$-syn in the pathophysiology of PD, the question of pathological specificity remains. Although $\alpha$-syn and LB-like pathology seen in autopsies and biopsies in $\mathrm{Gl}$ and brain tissue support the involvement and detection of PD, there is an important caveat that $\alpha$-syn immunoreactivity does not necessitate PD. Healthy individuals can display esophageal and spinal cord $\alpha$-syn immunoreactivity $[45,117,118]$. Furthermore, spinal cord $\alpha$-syn immunoreactivity was found alongside DMV and SN expression [118]. The DMV, which is the nexus of the gut-brain hypothesis, is also subject to pathological ambiguity with post-mortem brains exhibiting DMV $\alpha$-syn pathology, but only $30 \%$ of subjects having a history of

Table 1: Review of the various methods used to create enteric $\alpha$-syn PD models. $\alpha$-syn in wild type (WT), oligomer, monomer, or pre-formed fibril (PFF) forms were injected, at various volumes, concentrations, and amounts into the gastrointestinal tracts of Sprague-Daley (SD) rats, mice, or non-human primates (NHPs). Citation denoted in parenthesis.

\begin{tabular}{|c|c|c|c|c|c|c|c|}
\hline \multicolumn{8}{|c|}{ Enteric $\alpha$-syn Animal Models } \\
\hline & $\begin{array}{l}\text { Animal(s) } \\
\text { used }\end{array}$ & $\begin{array}{l}\text { a-syn } \\
\text { Source(s) }\end{array}$ & a-synType(s) & Concentration(s) & $\begin{array}{l}\text { Injection } \\
\text { Volume }\end{array}$ & $\begin{array}{l}\text { Injection } \\
\text { Number }\end{array}$ & $\begin{array}{l}\text { Injection } \\
\text { site(s) }\end{array}$ \\
\hline $\begin{array}{l}\text { Holmqvist, et } \\
\text { al. [111] }\end{array}$ & SD Rats & Human & $\begin{array}{l}\text { WT, } \\
\text { oligomer, \& } \\
\text { PFF }\end{array}$ & $\begin{array}{l}2 \mu \mathrm{g} / \mu \mathrm{l}, \\
1 \mu \mathrm{g} / \mu \mathrm{l}, \\
\& 1 \mu \mathrm{g} / \mu \mathrm{l}\end{array}$ & $3 \mu \mathrm{L}$ & 5 & $\begin{array}{l}\text { Stomach \& } \\
\text { duodenum }\end{array}$ \\
\hline $\begin{array}{l}\text { Manfredsson, } \\
\text { et al. [112] }\end{array}$ & $\begin{array}{l}\text { SD Rats \& } \\
\text { NHP }\end{array}$ & $\begin{array}{l}\text { Mouse \& } \\
\text { human }\end{array}$ & $\begin{array}{l}\text { PFF \& } \\
\text { monomer }\end{array}$ & $2 \mu \mathrm{g} / \mu \mathrm{L}$ & $5 \mu \mathrm{L}$ & 6 & $\begin{array}{l}\text { Descending } \\
\text { colon }\end{array}$ \\
\hline $\begin{array}{l}\text { Uemura, et al. } \\
\text { [113] }\end{array}$ & $\begin{array}{l}\text { C57BL/6J } \\
\text { Mice }\end{array}$ & Mouse & PFF & $2 \mu \mathrm{g} / \mu \mathrm{L}$ & $3 \mu \mathrm{L}$ & 8 & Gastric wall \\
\hline $\begin{array}{l}\text { Van Den } \\
\text { Berge, et al. } \\
{[114]}\end{array}$ & SD Rats & Human & $\begin{array}{l}\text { WT \& S129A } \\
\text { mutant }\end{array}$ & $1 \mu \mathrm{g} / \mu \mathrm{L}$ & $3 \mu \mathrm{L}$ & 6 & $\begin{array}{l}\text { Pylorus \& } \\
\text { duodenum }\end{array}$ \\
\hline Kim, et al.[115] & $\begin{array}{l}\text { C57BL/6J } \\
\text { Mice }\end{array}$ & Mouse & PFF & $2.5 \mu \mathrm{g} / \mu \mathrm{L}$ & $2.5 \mu \mathrm{L}$ & 4 & $\begin{array}{l}\text { Pylorus \& } \\
\text { duodenum }\end{array}$ \\
\hline $\begin{array}{l}\text { Challis, et } \\
\text { al.[116] }\end{array}$ & $\begin{array}{l}\text { C57BL/6N } \\
\text { Mice }\end{array}$ & Mouse & $\begin{array}{l}\text { PFF \& } \\
\text { monomer }\end{array}$ & $1 \mu \mathrm{g} / \mu \mathrm{L}$ & $3 \mu \mathrm{L}$ & 2 & Duodenum \\
\hline
\end{tabular}


Table 2: Locations and times where $\alpha$-syn was located following gastrointestinal (GI) injections. Following the injection of $\alpha$-syn into the GI tracts in various paradigms animals were sacked at period of hours postinjection (HPI), days postinjection (DPI) and months postinjection (MPI). Thereafter, the various studies located $\alpha$-syn in the GI, vagus nerve (VN), dorsal motor nucleus of the vagus (DMV), locus coeruleus (LC), substantia nigra pars compacts (SNpc), amygdale (AM), olfactory bulbs (OB), hippocampus $(\mathrm{HC})$, striatum (ST), hypothalamus (HT), entorhinal cortex (EC), motor cortex (MC), and prefrontal cortex (PFC). In some instances, a-syn pathology was not observed (NO) as in non-human primates (NHPs). Citation number denoted in parenthesis.

\begin{tabular}{|c|c|c|c|c|c|c|c|c|c|c|c|c|c|c|}
\hline \multicolumn{15}{|c|}{ a-syn Immunoreactivity Locations and Times } \\
\hline & GI & VN & DMV & LC & SNpc & AM & MO & OB & $\mathrm{HC}$ & ST & HT & EC & MC & PFC \\
\hline $\begin{array}{l}\text { Holmqvist, et al. } \\
\text { [111] }\end{array}$ & $\begin{array}{l}12 \\
\mathrm{HPI}\end{array}$ & $\begin{array}{l}48 \\
144 \\
\text { HP1 }\end{array}$ & $\begin{array}{l}144 \\
\text { HP1 }\end{array}$ & - & - & - & - & - & - & - & - & - & - & - \\
\hline $\begin{array}{l}\text { Manfredsson, et } \\
\text { al. [112] }\end{array}$ & $\begin{array}{l}\text { 1- } \\
12 \\
\text { MP1 }\end{array}$ & - & $\begin{array}{l}1 \mathrm{MPI} \\
\mathrm{NO} 12 \\
\mathrm{MPI}) \\
(\mathrm{NHPS}\end{array}$ & $\begin{array}{l}1 \\
\mathrm{MPI}\end{array}$ & - & - & - & - & - & - & - & - & - & - \\
\hline $\begin{array}{l}\text { Uemura, et al. } \\
\text { [113] }\end{array}$ & $\begin{array}{l}45 \\
\text { DPI }\end{array}$ & - & $\begin{array}{l}45 \\
D P I\end{array}$ & - & - & - & - & - & - & - & - & - & - & - \\
\hline $\begin{array}{l}\text { Van Den Berge, } \\
\text { et al. [114] }\end{array}$ & $\begin{array}{l}4 \\
\mathrm{MPI}\end{array}$ & - & $4 \mathrm{MPI}$ & $\begin{array}{l}4 \\
\text { MPI }\end{array}$ & $4 \mathrm{MPI}$ & - & - & $\begin{array}{l}4 \\
\mathrm{MPI}\end{array}$ & $\begin{array}{l}4 \\
\mathrm{MPI}\end{array}$ & $\begin{array}{l}4 \\
\text { MPI }\end{array}$ & $\begin{array}{l}4 \\
\mathrm{MPI}\end{array}$ & $\begin{array}{l}4 \\
\mathrm{MPI}\end{array}$ & $4 \mathrm{MPI}$ & - \\
\hline Kim, et al. [115] & $\begin{array}{l}1 \\
\mathrm{MPI}\end{array}$ & - & $\begin{array}{l}1-10 \\
\text { MPI }\end{array}$ & $\begin{array}{l}1 \\
\mathrm{MPI}\end{array}$ & $\begin{array}{l}3,7 \\
\mathrm{MPI}\end{array}$ & $\begin{array}{l}3 \\
\mathrm{MPI}\end{array}$ & $\begin{array}{l}1- \\
10 \\
M P I\end{array}$ & $\begin{array}{l}1- \\
10 \\
\text { MPI }\end{array}$ & $\begin{array}{l}7 \& \\
10 \\
\text { MPI }\end{array}$ & $\begin{array}{l}7 \& \\
10 \\
M P I\end{array}$ & $\begin{array}{l}7 \\
\mathrm{MPI}\end{array}$ & - & - & $\begin{array}{l}3,7 \\
\& 10 \\
\text { MPI }\end{array}$ \\
\hline $\begin{array}{l}\text { Challis, et al. } \\
{[116]}\end{array}$ & $\begin{array}{l}21- \\
120 \\
\text { DPI }\end{array}$ & - & - & - & - & - & - & - & - & - & - & - & - & - \\
\hline
\end{tabular}

neurodegenerative disease [119]. Furthermore, a United Kingdom study of PD brains found that all samples lacked DMV $\alpha$-syn immunoreactivity despite being present in the SN and Nucleus Basalis of Meynert [120]. Braak and colleagues also found in a study of 301 individuals with PD-related pathology, that 19 in the cohort did not have brainstem pathology [121] although this was attributed to the vast majority having AD. Additionally, myenteric neurons, which often are the cells that exhibit GI $\alpha$-syn immunoreactivity, have been reported to be unaffected by $\alpha$-syn with unchanged neuronal abundance and a lack of neurodegeneration [122]. Moreover, the pragmatism of GI biopsies has been questioned given their superficial nature which often lacks the myenteric and submucosal plexuses [60]. In fact, colonic biopsies have been reported as poor indicators of PD since the exhibited immunoreactivity is not exclusive to PD [123] with biopsies concur reporting cases where $\alpha$-syn was expressed in GI tract of non-PD individuals [58]. As such, the clinical application or utility is uncertain, but methods are thought to evolve to be a pragmatic method of early PD detection [61].

Even as peripheral LBs in incidental LB disease are a noted marker of pre- symptomatic PD [124], the lack of specificity of LB and $\alpha$-syn pathology raises questions about its clinical diagnostic utility. The general lack of correlation between LB pathology and decreased neuronal abundance may be explained by the proposition that LB are neuroprotective [35]. For instance, some propose that a threshold of $L B / \alpha$-syn must be reached before neurodegeneration occurs [124]. This notion is indirectly surmised by evidence that $\alpha$-syn immunoreactivity can be present in asymptomatic PD patients [47]. However, it still remains an open question regarding the heterogeneity in brain pathology although some posit that the Braak hypothesis pertains to only a subset of PD patients [125]. Others hypothesize that the heterogeneity in DMV $\alpha$-syn pathology arises from two subsets they refer to as "CNS-first" and "PNS-first" mechanisms of PD initiation [126]. Likewise a "dual-hit hypothesis" comprising of an anterograde OB pathway and retrograde VN pathways via a neurotropic pathogen has been proposed [127]. This theorem agrees with previous findings by Braak and colleagues of concurrent $\mathrm{DMV}$ and $\mathrm{OB}$ inclusions [128]. Interestingly, the group later minimized the role of $O B$ in $\alpha$-syn brain inclusions [39]. As for pre-clinical studies, a review discussing the relevance of animal $\alpha$-syn overexpression models concluded that singular models bore a poor resemblance to both genetic and idiopathic PD [129]. Many of these animal models employed C57BI6 mice for their pragmatic genetic and research utility and have offered invaluable insights into $\alpha$-syn and its role in PD. Still, they can also create a bottleneck in the richness in speciation. That aside, the presentations from $\mathrm{Tg}$ and $\alpha$-syn overexpression models can diverge from the classical 
patterns of PD [129]. Moreover, the high volume and density of injected $\alpha$-syn may elicit cellular and molecular responses that differ from processes over time in PD. Another consideration about the typical models used, e.g., rats and mice, is the shorter VN relative to humans, which could result in faster and more extensive pathology in line with previous findings on translocation rates discussed by Holmqvist and colleagues [111]. This may underlie the lack of brain pathology in NHPs [112] with an assumption that it could requires years rather than months for $\alpha$-syn to reach the brain in larger mammals. Nonetheless, the diversity of models in recent studies including $\mathrm{Tg}$ and WT species of mice [113-116], rats $[111,114]$, and NHPs [112] have all underscored the ability of $\alpha$-syn to propagate up the VN to the brain. With that in mind, it is plausible that $\alpha$-syn propagation is not isolated merely to the VN. A study involving intramuscular injections of $\alpha$-syn-PFF and adeno-associated virus vectors (AAV) coincided with motor dysfunction and $\alpha$-syn expression in the sciatic nerve [130]. Other studies injecting $A A V$ into the $V N$ and midbrain observed retrograde spreading to the pons, midbrain, and forebrain [131] and anterograde spreading into the gastric wall [132]. These intriguing findings would imply that a whole-body mechanism may be involved in $\alpha$-syn propagation.

In conclusion, preclinical evidence supports vagus nerve propagation, but whether the GI and ENS are the sole source of $\alpha$-syn in PD remains to be delineated. Nevertheless, these studies have provided greater understanding of the pathophysiology underlying PD. At the same time, they also raise key questions about the validity underlying the hypothesis of enteric a-syn progression to the brain and PD manifestation. At the very least, it will continue to spur further effort and research in substantiating or revising this provocative notion in the pathophysiology underlying the emergence of Parkinson's Disease.

\section{Declaration of Disclosures}

Dr. Shin receives support from Hope Soars and Dinapoli Research Fund at Albany Medical Center.

\section{Authors' Role}

EK wrote the manuscript and conducted the literature review. KA and AA contributed to the writing and editing of the manuscript and assisted with the literature review. DS assisted in the writing, editing and literature review. He was also involved in the conceptual development of the review. All authors approved the final article.

\section{References}

1. Parkinson $\mathrm{J}$ (2002) An essay on the shaking palsy. 1817. J Neuropsychiatry Clin Neurosci 14: 223-236.

2. Hurwitz B (2019) Coinage of the eponym 'maladie de Parkinson'. Nat Rev Neurol 15: 243.
3. Bertram L, Tanzi RE (2005) The genetic epidemiology of neurodegenerative disease. J Clin Invest 115: 1449-1457.

4. Tysnes OB, Storstein A (2017) Epidemiology of Parkinson's disease. J Neural Transm 124: 901-905.

5. Hassler R (1938) Zur Pathologie der Paralysis agitans und des postenzephalitischen Parkinsonismus. Journal fur Psychologie und Neurologie 48: 387-476.

6. Postuma RB, Berg D, Stern M, Poewe W, Olanow CW, et al. (2015) MDS clinical diagnostic criteria for Parkinson's disease. Mov Disord 30: 1591-1601.

7. Goedert M, Spillantini MG, Del Tredici K, Braak H (2013) 100 years of Lewy pathology. Nat Rev Neurol 9: 13-24.

8. Trojanowski JQ, Goedert M, Iwatsubo T, Lee VM (1998) Fatal attractions: Abnormal protein aggregation and neuron death in Parkinson's disease and Lewy body dementia. Cell Death Differ 5: 832-837.

9. Spillantini MG, Schmidt ML, Lee VMY, Trojanowski JQ, Jakes R, et al. (1997) a-Synuclein in Lewy bodies. Nature 388(6645): 839-840.

10. Goldman JE, Yen Sh, Chiu FC, Peress NS (1983) Lewy bodies of Parkinson's disease contain neurofilament antigens. Science 221: 1082-1084.

11. Kuzuhara S, Mori H, Izumiyama N, Yoshimura M, Ihara $Y$ (1988) Lewy bodies are ubiquitinated. Acta Neuropathologica 75: 345-353.

12. Parkkinen L, O'Sullivan SS, Collins C, Petrie A, Holton JL, et al. (2011) Disentangling the relationship between lewy bodies and nigral neuronal loss in Parkinson's disease. $\mathrm{J}$ Parkinson's Dis 1: 277-286.

13. Gomez-Tortosa E, Newell K, Irizarry MC, Albert M, Growdon $\mathrm{JH}$, et al. (1999) Clinical and quantitative pathologic correlates of dementia with Lewy bodies. Neurology 53: 1284-1291.

14. Maroteaux L, Campanelli JT, Scheller RH (1988) Synuclein: A neuron-specific protein localized to the nucleus and presynaptic nerve terminal. J Neurosci 8: 2804-2815.

15. Scott D, Roy S (2012) a-Synuclein inhibits intersynaptic vesicle mobility and maintains recycling-pool homeostasis. J Neurosci 32: 10129-10135.

16. Polymeropoulos MH, Lavedan C, Leroy E, Ide SE, Dehejia A, et al. (1997) Mutation in the $\alpha$-synuclein gene identified in families with Parkinson's disease. Science 276: 20452047.

17. Singleton $A B$, Farrer $M$, Johnson J, Singleton A, Hague $S$, et al. (2003) a-Synuclein locus triplication causes Parkinson's disease. Science 302: 841.

18. Satake W, Nakabayashi Y, Mizuta I, Hirota Y, Ito C, et al. (2009) Genome-wide association study identifies common variants at four loci as genetic risk factors for Parkinson's disease. Nat Genet 41: 1303-1307.

19. Nalls MA, Pankratz N, Lill CM, Do CB, Hernandez DG, et al. (2014) Large-scale meta-analysis of genome-wide association data identifies six new risk loci for Parkinson's disease. Nat Genet 46: 989-993.

20. Luk KC, Song C, O'Brien P, Stieber A, Branch JR, et al. (2009) Exogenous a-synuclein fibrils seed the formation of Lewy body-like intracellular inclusions in cultured cells. Proc Natl Acad Sci USA 106: 20051-20056.

21. Volpicelli-Daley LA, Luk KC, Patel TP, Tanik SA, Riddle DM, et al. (2011) Exogenous $\alpha$-Synuclein fibrils induce lewy body pathology leading to synaptic dysfunction and neuron 
death. Neuron 72: 57-71.

22. Luk KC, Kehm V, Carroll J, Zhang B, O'Brien P, et al. (2012) Pathological -synuclein transmission initiates Parkinson-like neurodegeneration in nontransgenic mice. Science 338: 949-953.

23. Shimozawa A, Ono M, Takahara D, Tarutani A, Imura S, et al. (2017) Propagation of pathological a-synuclein in marmoset brain. Acta Neuropathol Commun 5: 12.

24. Peelaerts W, Bousset L, Van Der Perren A, Moskalyuk A, Pulizzi R, et al. (2015) a-Synuclein strains cause distinct synucleinopathies after local and systemic administration. Nature 522: 340-344.

25. Thakur P, Breger LS, Lundblad M, Wan OW, Mattsson B, et al. (2017) Modeling Parkinson's disease pathology by combination of fibril seeds and a-synuclein overexpression in the rat brain. Proc Natl Acad Sci 114: E8284-E8293.

26. Zhang W, Wang T, Pei Z, Miller DS, Wu X, et al. (2005) Aggregated $\alpha$-synuclein activates microglia: A process leading to disease progression in Parkinson's disease. FASEB J 19: 533-542.

27. Kramer ML, Schulz-Schaeffer WJ (2007) Presynaptic a-synuclein aggregates, not Lewy bodies, cause neurodegeneration in dementia with lewy bodies. J Neurosci 27: 1405-1410.

28. Chu Y, Le W, Kompoliti K, Jankovic J, Mufson EJ, et al (2006) Nurr1 in Parkinson's disease and disorders. J Comp Neurol 494: 495-514.

29. Chen L, Thiruchelvam MJ, Madura K, Richfield EK (2006) Proteasome dysfunction in aged human a-synuclein transgenic mice. Neurobiol Dis 23: 120-126.

30. Chu Y, Kordower JH (2007) Age-associated increases of a-synuclein in monkeys and humans are associated with nigrostriatal dopamine depletion: Is this the target for Parkinson's disease? Neurobiol Dis 25: 134-149.

31. Fishbein I, Kuo YM, Giasson BI, Nussbaum RL (2014) Augmentation of phenotype in a transgenic Parkinson mouse heterozygous for a Gaucher mutation. Brain 137: 32353247.

32. Martin LJ, Pan Y, Price AC, Sterling W, Copeland NG, et al. (2006) Parkinson's disease $\alpha$-synuclein transgenic mice develop neuronal mitochondrial degeneration and cell death. J Neurosci 26: 41-50.

33. Wong YC, Krainc D (2017) $\alpha$-synuclein toxicity in neurodegeneration: Mechanism and therapeutic strategies. Nat Med 23: 1-13.

34. Greten-Harrison B, Polydoro M, Morimoto-Tomita M, Diao L, Williams AM, et al. (2010) aßy-Synuclein triple knockout mice revealage-dependent neuronal dysfunction. Proc Natl Acad Sci USA 107: 19573-19578.

35. Chen L, Feany MB (2005) $\alpha$-synuclein phosphorylation controls neurotoxicity and inclusion formation in a Drosophila model of Parkinson disease. Nat Neurosci 8: 657-663.

36. Chen H, Zhao EJ, Zhang W, Lu Y, Liu R, et al. (2015) Meta-analyses on prevalence of selected Parkinson's nonmotor symptoms before and after diagnosis. Transl Neurodegener 4: 1 .

37. Pfeiffer RF (2011) Gastrointestinal dysfunction in Parkinson's disease. Parkinsonism Relat Disord 17: 10-15.

38. Braak H, De Vos RAI, Bohl J, Del Tredici K (2006) Gastric a-synuclein immunoreactive inclusions in Meissner's and Auerbach's plexuses in cases staged for Parkinson's dise- ase-related brain pathology. Neurosci Lett 396: 67-72.

39. Braak H, Del Tredici K, Rüb U, De Vos RAI, Jansen Steur ENH, et al. (2003) Staging of brain pathology related to sporadic Parkinson's disease. Neurobiol Aging 24: 197-211.

40. Braak H, Ghebremedhin E, Rüb U, Bratzke H, Del Tredici K (2004) Stages in the development of Parkinson's disease-related pathology. Cell Tissue Res 318: 121-134.

41. Kay S, Josefine M, Siswanto S, Reijko K, Helmut H, et al. (2015) The brainstem pathologies of Parkinson's disease and dementia with Lewy bodies. Brain Pathol 20: 1878-1891.

42. Qualman SJ, Haupt HM, Yang P, Hamilton SR (1984) Esophageal Lewy bodies associated with ganglion cell loss in achalasia. Similarity to Parkinson's disease. Gastroenterology 87: 848-856.

43. Wakabayashi K, Takahashi H, Takeda S, Ohama E, Ikuta F (1988) Parkinson's disease: The presence of Lewy bodies in Auerbach's and Meissner's plexuses. Acta Neuropathol 76: 217-221.

44. Wakabayashi K, Takahashi H, Ohama E, Takeda S, Ikuta $F$ (1993) Lewy bodies in the visceral autonomic nervous system in Parkinson's disease. Adv Neurol 60: 609-612.

45. Tanei ZI, Saito Y, Ito S, Matsubara T, Motoda A, et al. (2020) Lewy pathology of the esophagus correlates with the progression of Lewy body disease: A Japanese cohort study of autopsy cases. Acta Neuropathol 141: 25-37.

46. Beach TG, Adler CH, Sue LI, Vedders L, Lue L, et al. (2010) Multi-organ distribution of phosphorylated alpha-synuclein histopathology in subjects with Lewy body disorders. Acta Neuropathol 119: 689-702.

47. Del Tredici K, Duda JE (2011) Peripheral Lewy body pathology in Parkinson's disease and incidental Lewy body disease: Four cases. J Neurol Sci 310: 100-106.

48. Wakabayashi K, Takahashi H, Ohama E, Ikuta F (1990) Parkinson's disease: An immunohistochemical study of Lewy body-containing neurons in the enteric nervous system. Acta Neuropathol 79: 581-583.

49. Ikemura M, Saito $Y$, Sengoku R, Sakiyama $Y$, Hatsuta $H$, et al. (2008) Lewy body pathology involves cutaneous nerves. J Neuropathol Exp Neurol 67: 945-953.

50. Del Tredici K, Hawkes $\mathrm{CH}$, Ghebremedhin E, Braak H (2010) Lewy pathology in the submandibular gland of individuals with incidental Lewy body disease and sporadic Parkinson's disease. Acta Neuropathol 119: 703-713.

51. Gray MT, Munoz DG, Gray DA, Schlossmacher MG, Woulfe JM (2014) Alpha-synuclein in the appendiceal mucosa of neurologically intact subjects. Mov Disord 29: 991-998.

52. Mendes A, Gonçalves A, Vila-Chã N, Moreira I, Fernandes $\mathrm{J}$, et al. (2015) Appendectomy may delay Parkinson's disease onset. Mov Disord 30: 1404-1407.

53. Gelpi E, Navarro-Otano J, Tolosa E, Gaig C, Compta Y, et al. (2014) Multiple organ involvement by alpha-synuclein pathology in Lewy body disorders. Mov Disord 29: 10101018.

54. Stakenborg N, Boeckxstaens G, Matteoli G (2013) The versatile role of the vagus nerve in the gastrointestinal tract.

55. Chandra R, Hiniker A, Kuo YM, Nussbaum RL, Liddle RA (2017) a-Synuclein in gut endocrine cells and its implications for Parkinson's disease. JCI Insight 2: 1-13.

56. Bohórquez DV, Shahid RA, Erdmann A, Kreger AM, Wang $Y$, et al. (2015) Neuroepithelial circuit formed by innervation of sensory enteroendocrine cells. J Clin Invest 125: 782- 
786.

57. Stokholm MG, Danielsen EH, Hamilton-Dutoit SJ, Borghammer $P$ (2016) Pathological $\alpha$-synuclein in gastrointestinal tissues from prodromal Parkinson disease patients. Ann Neurol 79: 940-949.

58. Yan F, Chen Y, Li M, Wang Y, Zhang W, et al. (2018) Gastrointestinal nervous system a-synuclein as a potential biomarker of Parkinson disease. Medicine 97: e11337.

59. Kim JS, Kim JS, Park IS, Park IS, Park HE, et al. (2017) a-Synuclein in the colon and premotor markers of Parkinson disease in neurologically normal subjects. Neurol Sci 38: 171-179.

60. Tsukita K, Sakamaki-Tsukita H, Tanaka K, Suenaga T, Takahashi R (2019) Value of in vivo a-synuclein deposits in Parkinson's disease: A systematic review and meta-analysis. Movement Disorders 34: 1452-1463.

61. Cersosimo MG (2015) Gastrointestinal biopsies for the diagnosis of alpha-synuclein pathology in Parkinson's disease. Gastroenterol Res Pract 2015: 476041.

62. Killinger BA, Madaj Z, Sikora JW, Rey N, Haas AJ, et al. (2018) The vermiform appendix impacts the risk of developing Parkinson's disease. Sci Transl Med 10.

63. Marras C, Lang AE, Austin PC, Lau C, Urbach DR (2016) Appendectomy in mid and later life and risk of Parkinson's disease: A population-based study. Mov Disord 31: 12431247.

64. Svensson E, Horváth-Puhó E, Stokholm MG, Sørensen HT, Henderson VW, et al. (2016) Appendectomy and risk of Parkinson's disease: A nationwide cohort study with more than 10 years of follow-up. Mov Disord 31: 1918-1922.

65. Svensson E, Horváth-Puhó E, Thomsen RW, Djurhuus JC, Pedersen L, et al. (2015) Vagotomy and subsequent risk of Parkinson's disease. Ann Neurol 78: 522-529.

66. Tysnes OB, Kenborg L, Herlofson K, Steding-Jessen M, Horn A, et al. (2015) Does vagotomy reduce the risk of Parkinson's disease? Ann Neurol 78: 1011-1012.

67. Liu B, Fang F, Pedersen NL, Tillander A, Ludvigsson JF, et al. (2017) Vagotomy and Parkinson disease: A Swedish register-based matched-cohort study. Neurology 88: 19962002.

68. Tan AH, Mahadeva S, Thalha AM, Gibson PR, Kiew CK, et al. (2014) Small intestinal bacterial overgrowth in Parkinson's disease. Parkinsonism Relat Disord 20: 535-540.

69. Breen DP, Halliday GM, Lang AE (2019) Gut-brain axis and the spread of $\alpha$-synuclein pathology: Vagal highway or dead end? Mov Disord 34: 307-316.

70. Roy Sarkar S, Banerjee S (2019) Gut microbiota in neurodegenerative disorders. J Neuroimmunol 328: 98-104.

71. Fitzgerald E, Murphy S, Martinson HA (2019) Alpha-synuclein pathology and the role of the microbiota in Parkinson's disease. Front Neurosci 13: 369.

72. Elfil M, Kamel S, Kandil M, Koo BB, Schaefer SM (2020) Implications of the gut microbiome in Parkinson's disease. Mov Disord 35: 921-933.

73. Hill-Burns EM, Debelius JW, Morton JT, Wissemann WT, Lewis MR, et al. (2017) Parkinson's disease and Parkinson's disease medications have distinct signatures of the gut microbiome. Mov Disord 32: 739-749.

74. Keshavarzian A, Green SJ, Engen PA, Voigt RM, Naqib A, et al. (2015) Colonic bacterial composition in Parkinson's disease. Mov Disord 30: 1351-1360.
75. Weis S, Schwiertz A, Unger MM, Becker A, Faßbender K, et al. (2019) Effect of Parkinson's disease and related medications on the composition of the fecal bacterial microbiota. npj Parkinson's Disease 5.

76. Hasegawa S, Goto S, Tsuji H, Okuno T, Asahara T, et al. (2015) Intestinal dysbiosis and lowered serum lipopolysaccharide-binding protein in Parkinson's disease. PLoS One 10: e0142164.

77. Aho VTE, Pereira PAB, Voutilainen S, Paulin L, Pekkonen E, et al. (2019) Gut microbiota in Parkinson's disease: Temporal stability and relations to disease progression. EBioMedicine 44: 691-707.

78. Luu M, Weigand K, Wedi F, Breidenbend C, Leister H, et al. (2018) Regulation of the effector function of CD8(+) T cells by gut microbiota-derived metabolite butyrate. Scientific Reports 8.

79. Forsyth CB, Shannon KM, Kordower JH, Voigt RM, Shaikh $M$, et al. (2011) Increased intestinal permeability correlates with sigmoid mucosa alpha-synuclein staining and endotoxin exposure markers in early Parkinson's disease. PLoS One 6: e28032.

80. Stypuła G, Kunert-Radek J, Stepień H, Zylińska K, Pawlikowski M (1996) Evaluation of interleukins, ACTH, cortisol and prolactin concentrations in the blood of patients with parkinson's disease. Neuroimmunomodulation 3: 131134.

81. Rydbirk R, Elfving B, Andersen MD, Langbøl MA, Folke J, et al. (2017) Cytokine profiling in the prefrontal cortex of Parkinson's disease and multiple system atrophy patients. Neurobiol Dis 106: 269-278.

82. Rentzos M, Nikolaou C, Andreadou E, Paraskevas GP, Rombos A, et al. (2007) Circulating interleukin-15 and RANTES chemokine in Parkinson's disease. Acta Neurol Scand 116: 374-379.

83. Devos D, Lebouvier T, Lardeux B, Biraud M, Rouaud T, et al. (2013) Colonic inflammation in Parkinson's disease. Neurobiol Dis 50: 42-48.

84. Brudek T (2019) Inflammatory bowel diseases and Parkinson's disease. J Parkinson's Dis 9: S331-S344.

85. Mishima T, Fukae J, Fujioka S, Inoue K, Tsuboi Y (2017) The prevalence of constipation and irritable bowel syndrome in Parkinson's disease patients according to rome ii diagnostic criteria. J Parkinson's Dis 7: 353-357.

86. Fasano A, Visanji NP, Liu LWC, Lang AE, Pfeiffer RF (2015) Gastrointestinal dysfunction in Parkinson's disease. Lancet Neurol 14: 625-639.

87. Rite I, Machado A, Cano J, Venero JL (2007) Blood-brain barrier disruption induces in vivo degeneration of nigral dopaminergic neurons. J Neurochem 101: 1567-1582.

88. Dardiotis E, Tsouris Z, Mentis AFA, Siokas V, Michalopoulou A, et al. (2018) H. pylori and Parkinson's disease: Meta-analyses including clinical severity. Clin Neurol Neurosurg 175: 16-24.

89. Nielsen HH, Qiu J, Friis S, Wermuth L, Ritz B (2012) Treatment for Helicobacter pylori infection and risk of parkinson's disease in Denmark. Eur J Neurol 19: 864-869.

90. Huang HK, Wang JH, Lei WY, Chen CL, Chang CY, et al. (2018) Helicobacter pylori infection is associated with an increased risk of Parkinson's disease: A population-based retrospective cohort study. Parkinsonism Relat Disord 47: 26-31.

91. Ueki A, Otsuka M (2004) Life style risks of Parkinson's di- 
sease: Association between decreased water intake and constipation. J Neurol 251: vii18-vii23.

92. Abbott RD, Petrovitch H, White LR, Masaki KH, Tanner $\mathrm{CM}$, et al. (2001) Frequency of bowel movements and the future risk of Parkinson's disease. Neurology 57: 456-462.

93. Savica R, Carlin JM, Grossardt BR, Bower JH, Ahlskog JE, et al. (2009) Medical records documentation of constipation preceding Parkinson disease: A case- control study. Neurology 73 : $1752-1758$.

94. Jost WH (2010) Gastrointestinal dysfunction in Parkinson's Disease. J Neurol Sci 289: 69-73.

95. Scheperjans F, Aho V, Pereira PAB, Koskinen K, Paulin L, et al. (2015) Gut microbiota are related to Parkinson's disease and clinical phenotype. Mov Disord 30: 350-358.

96. Cassani E, Privitera G, Pezzoli G, Pusani C, Madio C, et al. (2011) Use of probiotics for the treatment of constipation in Parkinson's disease patients. Minerva Gastroenterol Dieto 57: $117-121$

97. Tan AH, Lim SY, Chong KK, Azhan A Manap MA, Hor JW, et al. (2021) Probiotics for constipation in Parkinson's disease: A randomized placebo-controlled study. Neurology 96: e772-e782.

98. Ibrahim A, Ali RAR, Manaf MRA, Ahmad N, Tajurruddin FW, et al. (2020) Multi-strain probiotics (Hexbio) containing MCP BCMC strains improved constipation and gut motility in Parkinson's disease: A randomised controlled trial. PLoS One 15: e0244680.

99. Huang $\mathrm{H}, \mathrm{Xu} \mathrm{H}$, Luo Q, He J, Li M, et al. (2019) Fecal microbiota transplantation to treat Parkinson's disease with constipation: A case report. Medicine 98: e16163.

100. Xue LJ, Yang XZ, Tong Q, Shen P, Ma SJ, et al. (2020) Fecal microbiota transplantation therapy for Parkinson's disease: A preliminary study. Medicine (Baltimore) 99: e22035.

101. Van Laar T, Boertien JM, Herranz AH (2019) Faecal transplantation, pro- and prebiotics in Parkinson's disease; Hope or hype? J Parkinson's Dis 9: S371-S379.

102. Qin L, Wu X, Block ML, Liu Y, Breese GR, et al. (2007) Systemic LPS causes chronic neuroinflammation and progressive neurodegeneration. Glia 55: 453-462.

103. Kim C, Lv G, Lee JS, Jung BC, Masuda-Suzukake M, et al. (2016) Exposure to bacterial endotoxin generates a distinct strain of $\alpha$-synuclein fibril. Sci Rep 6: 30891.

104. Chen SG, Stribinskis V, Rane MJ, Demuth DR, Gozal E, et al. (2016) Exposure to the functional bacterial amyloid protein curli enhances alpha-synuclein aggregation in aged fischer 344 rats and caenorhabditis elegans. Sci Rep 6: 34477.

105. Ho L, Zhao D, Ono K, Ruan K, Mogno I, et al. (2019) Heterogeneity in gut microbiota drive polyphenol metabolism that influences $\alpha$-synuclein misfolding and toxicity. J Nutr Biochem 64: 170-181.

106. Erny $D$, De Angelis ALH, Jaitin D, Wieghofer $P$, Staszewski O, et al. (2015) Host microbiota constantly control maturation and function of microglia in the CNS. Nature Neuroscience 18: 965-977.

107. Choi I, Zhang Y, Seegobin SP, Pruvost M, Wang Q, et al. (2020) Microglia clear neuron-released $\alpha$-synuclein via selective autophagy and prevent neurodegeneration. Nat Commun 11: 1-14.

108. Sampson TR, Debelius JW, Thron T, Janssen S, Shastri
GG, et al. (2016) Gut microbiota regulate motor deficits and neuroinflammation in a model of Parkinson's disease. Cell 167: 1469-1480.

109. Rota L, Pellegrini C, Benvenuti L, Antonioli L, Fornai M, et al. (2019) Constipation, deficit in colon contractions and alpha-synuclein inclusions within the colon precede motor abnormalities and neurodegeneration in the central nervous system in a mouse model of alpha-synucleinopathy. Translational Neurodegeneration 8: 1-15.

110. Noorian AR, Rha J, Annerino DM, Bernhard D, Taylor GM, et al. (2012) Alpha- synuclein transgenic mice display age-related slowing of gastrointestinal motility associated with transgene expression in the vagal system. Neurobiol Dis 48: 9-19.

111. Holmqvist S, Chutna O, Bousset L, Aldrin-Kirk P, Li W, et al. (2014) Direct evidence of Parkinson pathology spread from the gastrointestinal tract to the brain in rats. Acta Neuropathol 128: 805-820.

112. Manfredsson FP, Luk KC, Benskey MJ, Gezer A, Garcia $\mathrm{J}$, et al. (2018) Induction of alpha-synuclein pathology in the enteric nervous system of the rat and non-human primate results in gastrointestinal dysmotility and transient CNS pathology. Neurobiol Dis 112: 106-118.

113. Uemura N, Yagi H, Uemura MT, Hatanaka Y, Yamakado $\mathrm{H}$, et al. (2018) Inoculation of $\alpha$-synuclein preformed fibrils into the mouse gastrointestinal tract induces Lewy body-like aggregates in the brainstem via the vagus nerve. Mol Neurodegener 13: 21.

114. Van Den Berge N, Ferreira N, Gram H, Mikkelsen TW, Alstrup AKO, et al. (2019) Evidence for bidirectional and trans-synaptic parasympathetic and sympathetic propagation of alpha-synuclein in rats. Acta Neuropathol 138: 535-550.

115. Kim S, Kwon SH, Kam TI, Panicker N, Karuppagounder SS, et al. (2019) Transneuronal propagation of pathologic a-Synuclein from the gut to the brain models Parkinson's disease. Neuron 103: 627-641.

116. Challis C, Hori A, Sampson TR, Yoo BB, Challis RC, et al. (2020) Gut- seeded a-synuclein fibrils promote gut dysfunction and brain pathology specifically in aged mice. Nat Neurosci 23: 327-336.

117. Bloch A, Probst A, Bissig H, Adams H, Tolnay M (2006) Alpha-synuclein pathology of the spinal and peripheral autonomic nervous system in neurologically unimpaired elderly subjects. Neuropathol Appl Neurobiol 32: 284-295.

118. Klos KJ, Ahlskog JE, Josephs KA, Apaydin H, Parisi JE, et al. (2006) $\alpha$ - Synuclein pathology in the spinal cords of neurologically asymptomatic aged individuals. Neurology 66: 1100-1102.

119. Parkkinen L, Kauppinen T, Pirttilä T, Autere JM, Alafuzoff I (2005) A-synuclein pathology does not predict extrapyramidal symptoms or dementia. Ann Neurol 57: 82-91.

120. Kalaitzakis ME, Graeber MB, Gentleman SM, Pearce RKB (2008) The dorsal motor nucleus of the vagus is not an obligatory trigger site of Parkinson's disease: A critical analysis of alpha-synuclein staging. Neuropathol Appl Neurobiol 34: 284-295.

121. Braak $H$, Müller $C M$, Rüb $U$, Ackermann $H$, Bratzke $H$, et al. (2006) Pathology associated with sporadic Parkinson's disease - where does it end? J Neural Transm Suppl 89-97.

122. Annerino DM, Arshad S, Taylor GM, Adler $\mathrm{CH}$, Beach TG, et al. (2012) Parkinson's disease is not associated with gastrointestinal myenteric ganglion neuron loss. Acta 
Neuropathol 124: 665-680.

123. Visanji NP, Marras C, Kern DS, Al Dakheel A, Gao A, et al. (2015) Colonic mucosal a-synuclein lacks specificity as a biomarker for Parkinson disease. Neurology 84: 609616.

124. Dickson DW, Fujishiro H, Delle Donne A, Menke J, Ahmed Z, et al. (2008) Evidence that incidental Lewy body disease is pre-symptomatic Parkinson's disease. Acta Neuropathol 115: 437-444.

125. Jellinger KA (2019) Is Braak staging valid for all types of Parkinson's disease? J Neural Transm 126: 423-431.

126. Borghammer P, Van Den Berge N (2013) Brain-first versus gut-first Parkinson's disease: A hypothesis. J Parkinson's Dis 9: S281-S295.

127. Hawkes CH, Del Tredici K, Braak H (2007) Parkinson's disease: A dual-hit hypothesis. Neuropathol Appl Neurobiol 33: $599-614$

128. Braak H, Del Tredici K, Bratzke H, Hamm-Clement J, Sandmann-Keil D, et al. (2002) Staging of the intracere- bral inclusion body pathology associated with idiopathic Parkinson's disease (preclinical and clinical stages). J Neurol 249: III/1-5.

129. Chesselet MF (2008) In vivo alpha-synuclein overexpression in rodents: A useful model of Parkinson's disease? Exp Neurol 209: 22-27.

130. Sacino AN, Brooks M, Thomas MA, McKinney AB, Lee S, et al. (2014) Intramuscular injection of a-synuclein induces CNS a-synuclein pathology and a rapid- onset motor phenotype in transgenic mice. Proc Natl Acad Sci USA 111: 10732-10737.

131. Ulusoy A, Rusconi R, Pérez-Revuelta BI, Musgrove RE, Helwig M, et al. (2013) Caudo-rostral brain spreading of a-synuclein through vagal connections. EMBO Mol Med 5: 1119-1127.

132. Ulusoy A, Phillips RJ, Helwig M, Klinkenberg M, Powley TL, et al. (2013) Brain-to-stomach transfer of $\alpha$-synuclein via vagal preganglionic projections. Acta Neuropathol 133: 381-393. 